\title{
REVIEW
}

\section{Methods, advantages, and limitations of body cooling for exercise performance}

\section{F E Marino}

Br J Sports Med 2002;36:89-94

Precooling studies confirm that increasing body heat is a limiting factor during exercise. However, it seems that precooling is only beneficial for endurance exercise of up to 30-40 minutes rather than intermittent or short duration exercise.

$T$ he relevant literature for this review was identified and selected using Medline (19662001), SPORT Discus (1949-2001), searching of journal articles and reference lists, and world wide web searches using various search engines identifying key databases and online journals. The literature cited was selected mainly on the basis of relevance to exercise performance and with some historical merit.

The tolerance of the human organism to high heat load has been studied in a range of situations, both at rest and during exercise and with a range of strategies designed to either reduce the heat load or enable the participant to cope with the debilitating effects of heat stress. From these studies it is well established that exercise is prematurely terminated in the heat. To address this problem, several specific approaches have been used either experimentally or in the field to manage or offset this reduction in performance during exercise heat stress. The approaches most used in experimental settings and in the field are acclimation and fluid ingestion (for a review, see Kay and Marino ${ }^{1}$ ). In contrast, whole body precooling, a method used to reduce body temperature before exercise, has been primarily used in experimental settings. ${ }^{2-4}$

$$
\begin{aligned}
& \text { "It is well established that exercise is } \\
& \text { prematurely terminated in the heat." }
\end{aligned}
$$

The basis of the precooling strategy is to reduce body temperature before exercise, thereby increasing the margin for metabolic heat production and increasing the time to reach the critical limiting temperature when a given exercise intensity can no longer be maintained. ${ }^{5}$ Most precooling studies have been conducted under moderate environmental conditions (range $\left.18-24^{\circ} \mathrm{C}\right),{ }^{346-8}$ with studies evaluating the usefulness of precooling under warm conditions only recently reported. ${ }^{29-11}$ Generally, precooling has been shown to increase time to exhaustion or increase the distance run or cycled (table 1). However, this area is awash with various methods of precooling (such as cold air, water immersion, water perfused suits), different exercise protocols, and environmental conditions. Owing to these variations in methodology and the degree of uncertainty about the mechanisms by which precooling enhances exercise performance, the practical application of precooling is yet to be fully assessed.

Therefore the purpose of this review is to discuss the current methods of precooling, the effects on exercise performance, and the physiological relations that are to date thought to contribute to enhanced exercise capacity through a precooling manoeuvre.

\section{PRECOOLING: THEORY AND METHODS}

Because prolonged exercise causes body temperature to rise in proportion to the metabolic rate, the increase in core temperature $\left(T_{c}\right)$ occurs rapidly and reaches steady state values when heat production equates to heat loss. It is now apparent that a critical limiting temperature exists as subjects either reduce their exercise intensity or change their pacing strategy so that exercise can continue with a reduced risk of cellular injury or heat related illness. This seems to be the case regardless of training state or acclimation. ${ }^{5}{ }^{12}$ In hot conditions, this situation is exacerbated and will ultimately result in premature termination of exercise or failure to complete the event. Therefore, as the absolute heat storage limits the duration of exercise at a given intensity, it would be prudent to start exercise with as cool a body temperature as possible. Whole body cooling before exercise (precooling) would be expected to widen the temperature margin before the critical limiting temperature is reached.

At first glance it would appear that precooling is a relatively recent intervention strategy. However, the benefits of precooling were studied more than 60 years ago, ${ }^{13}$ albeit not to improve exercise performance. These studies were typically concerned with reducing thermal strain and examining the cooling effect on circulatory dynamics and oxygen consumption. ${ }^{14-17}$ It is difficult to ascertain the original method of precooling with respect to body cooling before exercise, although the concept of precooling was used by Veghte and Webb ${ }^{18}$ using both water immersion in a thin dry suit and air cooling with a special garment for subjects subsequently exposed to heat. This study is no doubt a precursor to the more recent studies on precooling. Although the study by Veghte and Webb ${ }^{18}$ was conducted under resting conditions, it showed that tolerance time for exposure to a high heat load $\left(71^{\circ} \mathrm{C}\right)$ was inversely related to the initial body temperature.

However, the study by Bergh and Ekblom ${ }^{6}$ was one of the first to evaluate the effect of precooling on subsequent exercise performance. A reduction 
Table 1 Summary of precooling studies and related methods and outcomes

\begin{tabular}{|c|c|c|c|c|c|c|}
\hline Study & Precooling method & Exercise protocol & $\begin{array}{l}\text { Pre-exercise } \\
\mathrm{T}_{\mathrm{c}}\end{array}$ & $\begin{array}{l}\Delta \mathrm{T}_{\mathrm{c}} \text { at end } \\
\text { exercise }\end{array}$ & $\begin{array}{l}\text { Ambient } \\
\text { conditions }\end{array}$ & Outcome/conclusions \\
\hline Bergh \& Ekblom ${ }^{6}$ & $\begin{array}{l}\text { Swimming water } \\
\text { temperature } 13-15^{\circ} \mathrm{C}\end{array}$ & $\begin{array}{l}\text { Arm \& leg exercise to } \\
\text { exhaustion within 5-8 min }\end{array}$ & $34.9^{\circ} \mathrm{C}^{*}$ & Not reported & $20-22^{\circ} \mathrm{C}$ & $\begin{array}{l}\text { Lowering } T_{c} \text { reduced physical } \\
\text { performance }\end{array}$ \\
\hline Cotter et al ${ }^{11}$ & $\begin{array}{l}\text { lce vest with and } \\
\text { without thigh cooling + } \\
\text { cold air } 3^{\circ} \mathrm{C}\end{array}$ & $\begin{array}{l}20 \text { min cycling at } 65 \% \\
\mathrm{~V}_{2} \mathrm{PEAK}+15 \text { min work } \\
\text { performance }(35 \text { min total } \\
\text { exercise) }\end{array}$ & $36.8^{\circ} \mathrm{C}^{*} \dagger$ & $1.7^{\circ} \mathrm{C}$ & $33^{\circ} \mathrm{C}$ & $\begin{array}{l}\text { Precooling reduced } \\
\text { physiological and psychphysical } \\
\text { strain and increased endurance } \\
\text { performance }\end{array}$ \\
\hline Booth et $\left.a\right|^{2}$ & $\begin{array}{l}\text { Water immersion } \\
23-24^{\circ} \mathrm{C}\end{array}$ & $\begin{array}{l}30 \text { min self paced treadmill } \\
\text { running }\end{array}$ & $36.7^{\circ} \mathrm{C} \dagger$ & $2.2^{\circ} \mathrm{C}$ & $\begin{array}{l}31.6^{\circ} \mathrm{C}, 60 \% \\
r h\end{array}$ & $\begin{array}{l}\text { Increased distance run in } 30 \mathrm{~min} \\
\text { by } 304 \mathrm{~m}(+4 \%) \text {. }\end{array}$ \\
\hline Booth et $a l^{10}$ & Water immersion $24^{\circ} \mathrm{C}$ & $\begin{array}{l}35 \text { min cycling at } 60 \% \\
\mathrm{VO}_{2} \text { PEAK }\end{array}$ & $36.4^{\circ} \mathrm{C}^{*}$ & $1.9^{\circ} \mathrm{C}$ & $\begin{array}{l}34.9^{\circ} \mathrm{C} \\
46.4 \% r h\end{array}$ & $\begin{array}{l}\text { Precooling had limited effect on } \\
\text { muscle metabolism }\end{array}$ \\
\hline Kay et al ${ }^{9}$ & Water immersion $24^{\circ} \mathrm{C}$ & 30 min cycling time trial & $\mathrm{O}^{\circ} \mathrm{C} \dagger$ & $1.0^{\circ} \mathrm{C}$ & $\begin{array}{l}31.4^{\circ} \mathrm{C} \\
60.2 \% r h\end{array}$ & $\begin{array}{l}\text { Precooling the skin alone } \\
\text { increased distance cycled by } \\
0.9 \mathrm{~km} \text { and increased rate of } \\
\text { heat storage }\end{array}$ \\
\hline Lee \& Haymes $^{8}$ & Cold air $5^{\circ} \mathrm{C}$ & $\begin{array}{l}\text { Running at } 82 \% \mathrm{VO}_{2} \mathrm{MAX} \text { to } \\
\text { exhaustion }\end{array}$ & $0.37^{\circ} \mathrm{C} \dagger$ & $1.5^{\circ} \mathrm{C}$ & $\begin{array}{l}24^{\circ} \mathrm{C}, 51-52 \% \\
r h\end{array}$ & $\begin{array}{l}\text { Precooling increased exercise } \\
\text { endurance and rate of heat } \\
\text { storage }\end{array}$ \\
\hline Schmidt \& Brück ${ }^{4}$ & Cold air $0^{\circ} \mathrm{C}$ & $\begin{array}{l}\text { Cycling with increasing } \\
\text { workload to exhaustion }\end{array}$ & $36.4^{\circ} \mathrm{C}^{*}$ & $0.6^{\circ} \mathrm{C}$ & $18^{\circ} \mathrm{C}$ & $\begin{array}{l}\text { Increased time to exhaustion and } \\
\text { work performed }\end{array}$ \\
\hline Hessemer et aP & Cold air $0^{\circ} \mathrm{C}$ & 60 min work rate test & $36.4^{\circ} \mathrm{C}^{*}$ & $0.4^{\circ} \mathrm{C}$ & $18^{\circ} \mathrm{C}$ & $\begin{array}{l}\text { Increased work rate following } \\
\text { precooling }\end{array}$ \\
\hline $\begin{array}{l}\text { Olschewski \& } \\
\text { Brück }^{3}\end{array}$ & Cold air $0^{\circ} \mathrm{C}$ & $\begin{array}{l}\text { Cycling with increasing } \\
\text { workload to exhaustion }\end{array}$ & $36.9^{\circ} \mathrm{C}^{*}$ & $0.4^{\circ} \mathrm{C}$ & $18^{\circ} \mathrm{C}, 50 \% r h$ & $\begin{array}{l}\text { Increased endurance time } \\
\text { following precooling }\end{array}$ \\
\hline $\begin{array}{l}\text { González-Alonso et } \\
a^{34}\end{array}$ & $\begin{array}{l}30 \text { min water } \\
\text { immersion }\end{array}$ & $\begin{array}{l}\text { Cycling at } 60 \% \mathrm{VO}_{2} \mathrm{MAX} \text { to } \\
\text { exhaustion }\end{array}$ & $35.9^{\circ} \mathrm{C}^{*}$ & $4.2^{\circ} \mathrm{C}$ & $40^{\circ} \mathrm{C}, 19 \% r h$ & $\begin{array}{l}\text { Performance time increased. } \\
\text { Exercise terminating at identical } \\
\mathrm{T}_{\mathrm{c}} \text { to control }\end{array}$ \\
\hline Marsh \& Sleivert ${ }^{29}$ & $\begin{array}{l}30 \text { min water } \\
\text { immersion }\end{array}$ & 70 second cycling power test & $36.4^{\circ} \mathrm{C} \dagger$ & $0.1^{\circ} \mathrm{C}$ & $29^{\circ} \mathrm{C}, 80 \% r h$ & $\begin{array}{l}\text { Mean } 70 \text { second power output } \\
\text { increased following precooling } \\
\text { by } 2.7 \%\end{array}$ \\
\hline Kruk et $a 2^{20}$ & Cold air $5^{\circ} \mathrm{C}$ & $\begin{array}{l}\text { Cycling at } 50 \% \mathrm{VO}_{2} \mathrm{MAX} \text { for } \\
30 \mathrm{~min}\end{array}$ & $37.0^{\circ} \mathrm{C} \dagger$ & $0.5^{\circ} \mathrm{C}$ & $5^{\circ} \mathrm{C}$ & $\begin{array}{l}\text { Precooling reduced exercise } \\
\text { capacity in a cold environment. }\end{array}$ \\
\hline
\end{tabular}

in oesophageal temperature $\left(\mathrm{T}_{\text {es }}\right)$ was achieved by having subjects swim in cold water $\left(13-15^{\circ} \mathrm{C}\right)$ for $15-25$ minutes. This method achieved reductions in $\mathrm{T}_{\text {es }}$ to approximately $35.8^{\circ} \mathrm{C}$ on one occasion and about $34.9^{\circ} \mathrm{C}$ on another, but changes in skin temperature $\left(\mathrm{T}_{\mathrm{sk}}\right)$ were not reported. The exercise protocol used was such that the subjects became exhausted within 5-8 minutes. Precooling did not improve work time but rather reduced it. The authors concluded that the cause of the decrease in performance was the reduction in peak oxygen uptake. However, it is also possible that the reduction in oxygen uptake was the result of impaired exercise performance rather than the cause. Moreover, reductions in $\mathrm{T}_{\mathrm{es}}$ were such that subjects were close to hypothermia, or actually hypothermic, rather than being in a state of cold stress $\left(\mathrm{T}_{\mathrm{c}}>35^{\circ} \mathrm{C}\right),{ }^{19}$ which may have had negative effects on the central nervous system (CNS). Also, precooling was achieved by exercising in cold water, which may have impacted on the subsequent exercise performance by using available substrates. In addition, the duration of the exercise protocol was probably not sufficient to invoke significant thermoregulatory effector responses and therefore cannot be considered a true precooling study with respect to exercise performance.

Table 1 summarises the various methods used for precooling. Predominantly studies evaluating precooling have used cold air exposure. ${ }^{34} 720$ Schmidt and Brück ${ }^{4}$ preceded the exercise period with two cold exposures at a chamber temperature that was near $0^{\circ} \mathrm{C}$ followed by quick rewarming intervals designed to reduce shivering imposed by the cold exposure.
Two subsequent studies ${ }^{37}$ that used a similar precooling manoeuvre exposed subjects to ambient temperatures of $5-10^{\circ} \mathrm{C}$ for periods of 15 min followed by rewarming periods that lasted up to 20 minutes. The rationale given for the intervening rewarming periods was to re-establish thermal comfort, reduce the shivering of subjects, and blunt the metabolic response while decreasing body temperature. The time taken for cooling the body in these studies ranged from 100 to 130 minutes. This method resulted in $T_{c}$ actually increasing during the precooling period, probably because of the warmer blood at the skin moving to the core as a consequence of vasoconstriction, and significant reductions in $\mathrm{T}_{c}$ were observed only after the start of exercise. Lee and Haymes ${ }^{8}$ used cold air $\left(5^{\circ} \mathrm{C}\right)$ cooling for up to 40 minutes with no rewarming periods. Again, $\mathrm{T}_{\mathrm{c}}$ increased significantly during the cooling period but decreased at the start of exercise. This phenomenon in which $\mathrm{T}_{\mathrm{c}}$ spontaneously decreases after cold exposure has been described as an afterdrop in $\mathrm{T}_{\mathrm{c}}$ and is a common occurrence during the rewarming phase of a cooling manoeuvre. ${ }^{21}{ }^{22}$

In addition to cold air cooling, several researchers have used water immersion as a method of precooling. Marino and Booth $^{23}$ proposed that precooling by water immersion be carried out with gradual reductions in water temperature in order that the abrupt responses of acute cold stress be attenuated. This method requires that water temperature is set at about $29^{\circ} \mathrm{C}$ and reduced over a 60 minute period at a rate not exceeding $2^{\circ} \mathrm{C}$ per 10 minutes. The rationale for the use of water immersion is that the rate of heat loss to water is 
estimated to be $2-4$ times greater than to air at the same temperature. ${ }^{24} 25$ Moreover, a water temperature of $23-24^{\circ} \mathrm{C}$ does not present a high skin-environment temperature gradient compared with $10^{\circ} \mathrm{C}$ air. In addition, water immersion has the advantage of skin temperature being clamped near water temperature so that a more uniform skin temperature results. This method of precooling seems to be better able to reduce $\mathrm{T}_{\mathrm{c}}$ during the immersion period than cold air cooling. However, an afterdrop in $T_{c}$ also occurs with water immersion cooling

Recently Drust et $a l^{26}$ precooled subjects by having them stand under a cold shower for 60 minutes. By reducing the water temperature from $28^{\circ} \mathrm{C}$ to $24^{\circ} \mathrm{C}\left(2^{\circ} \mathrm{C} / 20\right.$ minutes $)$, a reduction in rectal temperature $\left(\mathrm{T}_{\mathrm{re}}\right)$ of approximately $0.3^{\circ} \mathrm{C}$ was achieved. Interestingly an afterdrop in $\mathrm{T}_{\mathrm{re}}$ was also observed from the end of precooling to the onset of exercise, thereby effectively reducing the starting $\mathrm{T}_{\mathrm{re}}$ by approximately $0.6^{\circ} \mathrm{C}$. Other researchers have used an ice vest to precool subjects, ${ }^{11} 27$ and this has been shown to effectively reduce the $\mathrm{T}_{\mathrm{re}}$ and skin temperature from baseline values.

In summary, whole body precooling has been achieved by a variety of methods. Regardless of the method used, the practical application at present is limited because of the time required to achieve sufficient body cooling to improve exercise performance. Moreover, the varied methods and results of the body cooling procedures are not likely to appeal as a practical intervention strategy.

\section{PRECOOLING AND EXERCISE PERFORMANCE}

A major problem in evaluating the effectiveness of precooling on exercise performance is the type of exercise protocol used. Thus far, various exercise protocols have been used but few have evaluated actual exercise performance (table 1). Bergh and Ekblom ${ }^{6}$ used a combined leg and arm exercise protocol designed to exhaust subjects within 5-8 minutes after the precooling manoeuvre. In this study, work time was significantly reduced from 6.24 minutes (control) to 4.36 and 3.06 minutes after precooling that reduced body temperatures to 35.8 and $34.9^{\circ} \mathrm{C}$ respectively. Although exercise duration was significantly reduced after precooling, the combined arm and leg exercise protocol has limited practical application to exercise performance. The authors hypothesised that a possible explanation for the reduced exercise duration was the resulting lower muscle temperature $\left(\mathrm{T}_{\mathrm{m}}\right)$ of $36.5^{\circ} \mathrm{C}$ and $35.1^{\circ} \mathrm{C}$ for the two precooling manoeuvres, possibly resulting in impaired anaerobic power because of depressed enzyme activity. However, this mechanism is unlikely as Blomstrand $e t{ }^{28}$ have shown that cooler muscles are more prone to fatigue, with an associated higher muscle lactate content, suggesting increased rather than impaired glycolytic activity. Therefore it is unclear how a reduced $\mathrm{T}_{\mathrm{m}}$ before exercise may impact on persons required to perform short intense exercise bouts.

However, Marsh and Sleivert ${ }^{29}$ using a 70 second high intensity cycling trial requiring a mix of aerobic and anaerobic energy supply under warm $\left(29^{\circ} \mathrm{C}\right)$ humid conditions $(80 \%$ relative humidity; rh), found that up to 30 minutes of precooling improved performance by approximately 3.3\% compared with control conditions. It was speculated that the increase in performance was attributable to the cold induced vasoconstriction of the skin and a concomitant increase in central blood volume, possibly increasing muscle blood flow and metabolite removal, thereby sustaining higher exercise intensity. This explanation relies on muscle blood flow being a limiting factor during exercise. However, as shown previously, ${ }^{5}$ fatigue develops even though skeletal muscle blood flow is not reduced, so it is questionable that performance, even in short duration exercise, is enhanced by increased muscle blood flow caused by vasoconstriction of the skin. The finding that precooling enhanced 70 seconds of high intensity exercise in the heat is in contrast with the data of Ball $e a^{30}$ showing an improvement in $2 \times 30$ second high intensity sprints when performed in hot $\left(30^{\circ} \mathrm{C}\right)$ compared with moderate $\left(18.7^{\circ} \mathrm{C}\right)$ conditions. Interestingly, blood lactate and acid base status were not different, suggesting similar metabolic responses in each ambient condition. The authors speculated that the improvement in power output in the heat was related to enhanced force development characteristics of type I muscle fibres. Given these contradictory findings, it is difficult to imagine by what mechanism precooling enhances short intense exercise.

The effect of precooling on intermittent activity has also been evaluated. ${ }^{26}$ The exercise protocol was designed to simulate exercise conditions of a soccer game over $2 \times 45$ minute periods separated by a 15 minute intermission. Although the precooling manoeuvre reduced the starting $\mathrm{T}_{\mathrm{re}}$ by approximately $0.3^{\circ} \mathrm{C}$, this had limited effect, if any, on the physiological responses measured. The authors concluded that precooling is of no significant benefit for intermittent exercise of similar duration.

In contrast, studies designed to evaluate the effect of precooling on endurance exercise have shown favourable results. Hessemer et $^{\mathrm{al}} \mathrm{l}^{7}$ using a protocol that required subjects to cycle as hard as possible for 60 minutes at $60-100 \mathrm{~W}$, showed that precooled subjects had achieved a considerably higher rate of absolute work. In addition, work rate was found to be higher at all times after precooling. However, this study was performed under ambient temperatures $\left(\mathrm{T}_{\mathrm{a}}\right)$ of $18^{\circ} \mathrm{C}$. Similarly, Olschewski and Brück ${ }^{3}$ were able to increase the endurance time from about 19 minutes (control) to about 21 minutes after precooling, an improvement of $12 \%$. The protocol used in this study was an increasing workload to exhaustion followed by exercise at a work rate of $20 \mathrm{~W}$ for 10 minutes. Again, this study was performed at a $\mathrm{T}_{\mathrm{a}}$ of $18^{\circ} \mathrm{C}$.

Running exercise has been evaluated using a protocol requiring subjects to run at $82 \%$ of maximum oxygen uptake. ${ }^{8}$ After cold air precooling, exercise duration was increased from about 22 minutes to about 26 minutes, representing a $16 \%$ increase in endurance time. However, it is only recently that simulated exercise performance has been evaluated after precooling coupled with hot conditions ${ }^{2}\left(\mathrm{~T}_{\mathrm{a}}=32^{\circ} \mathrm{C}\right.$; $60 \% \mathrm{rh}$ ). The protocol used in this study required subjects to run as far as possible in 30 minutes while adjusting the treadmill speed. After precooling, the distance run increased from about $7250 \mathrm{~m}$ to about $7550 \mathrm{~m}$, an improvement of about 304 $\mathrm{m}(+4 \%)$. Moreover, an analysis of the recorded speeds indicates that subjects ran at higher speeds throughout the 30 minutes and were able to increase their speed toward the end of the trial, whereas, at best, speed could only be maintained during control conditions. These data indicate that the benefit of precooling may be that the athlete is able to draw on reserves later in the performance rather than just being able to maintain a given intensity or speed.

The same group has also extended this study by evaluating the usefulness of precooling on self paced cycling performance. ' In this study, participants cycled on their own bicycles mounted on a magnetically braked cycle trainer and were able to manipulate their speed and gear ratio as required. After precooling by water immersion, the distance cycled increased by approximately $0.9 \mathrm{~km}$ over the control trial ( 14.9 versus $15.8 \mathrm{~km}$ ). Again, it was evident that subjects were able to increase exercise intensity toward the end of the trial.

" . . .the benefit of precooling may be that the athlete is able to draw on reserves later in the performance $n$ just being able to maintain a given intensity or speed".

These two studies ${ }^{29}$ suggest that subjects use different pacing strategies according to the level of thermal strain and that this may account for the increased exercise intensity toward the final stages of the exercise bout. This follows the line of 
thought that there exists a mechanism by which a muscle reserve is available. ${ }^{31}$ However, it remains to be established how a muscle reserve is accomplished.

Although most studies have shown an enhanced exercise performance in the heat after a precooling manoeuvre, a recent study does not advocate body cooling before triathlons. ${ }^{32}$ Precooling was achieved by water immersion (temperature approximately $25.5^{\circ} \mathrm{C}$ ) before either simulated swimming for 15 minutes or cycling for 45 minutes at about $75 \% \mathrm{VO}_{2}$ PEAK. However, the authors did not report any exercise performance result. Their conclusion was based solely on the lack of difference in thermoregulatory and metabolic responses between precooling and control trials. Although the trials in this study were counterbalanced, water immersion precooling before swimming exercise in a similar water environment may not be prudent given that core temperature may be reduced beyond the limits that would be advantageous. Precooling before swimming may have also masked the benefits of reduced thermal strain for those subjects that completed the cycling phase of the experiment first. Furthermore, the running portion of the triathlon was not included in the design. This was based on the rationale that the benefits of a reduced thermal strain are diminished after 30 minutes of submaximal exercise.

On balance, the benefits for exercise performance from whole body precooling can only be inferred given that most studies have not used performance based exercise protocols (table 1). In addition, it is somewhat difficult to interpret the findings in the light of the range of ambient conditions that have been used. Further work must be completed using more practical performance protocols before firm conclusions can be drawn about the benefits of precooling for exercise performance.

\section{PRECOOLING, EXERCISE, AND HEAT STORAGE}

A major advantage of precooling is related to the artificially enhanced capacity for heat storage. Ordinarily, the body's capacity to store heat is limited and directly related to exercise intensity, body size, and metabolic heat production. However, the environmental conditions also impact on the heat storage capacity. This is particularly the case when ambient conditions are hot and humid. Nielsen ${ }^{33}$ has provided calculations that show that the rate of rise in body temperature is increased dramatically when ambient temperature is $>35^{\circ} \mathrm{C}$ and $\mathrm{rh}$ is $>$ $60 \%$. Under these conditions, the reduced temperature gradients between core, skin, and environment and reduced water vapour pressure diminish the potential for evaporation of sweat. In this scenario, the limit for body heat storage is reached faster at a given exercise intensity. Therefore, because the theoretical basis of precooling is to increase the margin for rising body temperature before a critical limit is reached, it follows that precooling would be prudent before prolonged exercise under warmer rather than cooler conditions. Given the theoretical basis of precooling, it is somewhat surprising that to date only few studies have evaluated its usefulness in relation to exercise performance in the heat (table 1).

Heat storage capacity is a critical factor in the outcome of precooling manoeuvres, and only a few studies have reported it. Olschewski and Brück ${ }^{3}$ calculated heat storage after a protocol consisting of increasing workload to exhaustion, which resulted in heat storage of about 380 and $263 \mathrm{~kJ} / \mathrm{m}^{2}$ for precooling and control trials respectively. Using a similar method of calculation, others ${ }^{15}$ have also shown increased heat storage during exercise after precooling, preheating, and control conditions. These authors calculated heat storage at 10 minute intervals and were able to show the advantage of precooling over either preheating or control even under low ambient conditions $\left(5^{\circ} \mathrm{C} ; 40 \% \mathrm{rh}\right)$. Although negative during the precooling manoeuvre, heat storage was significantly higher during exercise after precooling compared with either

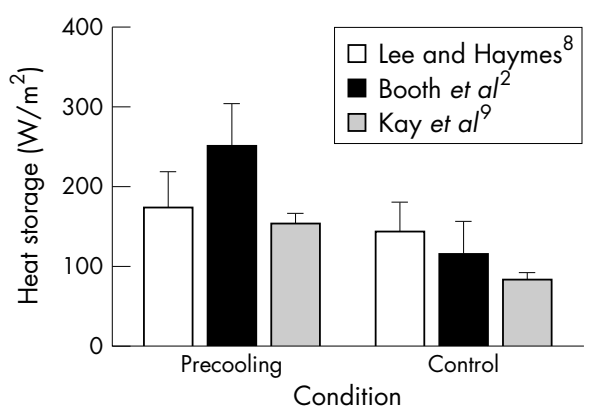

Figure 1 Rate of heat storage $\left(\mathrm{W} / \mathrm{m}^{2}\right)$ in three different studies. In all cases, it was significantly increased in the precooled condition compared with control conditions. Values are means (SD).

of the other two ambient conditions. However, exercise capacity was not enhanced by the higher heat storage but rather deteriorated. The authors suggested that the reduced exercise capacity was related to the low muscle temperature and low capacity for muscles to perform at these temperatures. However, muscle temperature was not actually measured but inferred from the measures of rectal and mean body temperatures.

Lee and Haymes ${ }^{8}$ reported heat storage as a rate per unit time during exercise after precooling. These researchers found that, during the actual precooling manoeuvre, heat storage was negative, but, like previous studies, it was increased significantly during the exercise period. Under moderate environmental conditions, the rate of heat storage was 144 and $119 \mathrm{~W} / \mathrm{m}^{2}$ for precooling and control conditions respectively. However, the fact that more sweat was evaporated during exercise after precooling than in control conditions $(75 \% \mathrm{v}$ $57 \%$ ) suggests that evaporative heat dissipation during exercise was more economical after precooling. Similarly, under hot humid conditions $\left(32^{\circ} \mathrm{C} ; 60 \% \mathrm{rh}\right)$, the rate of heat storage at the end of 30 minutes of running increased from about $113 \mathrm{~W} / \mathrm{m}^{2}$ for control conditions to about $250 \mathrm{~W} / \mathrm{m}^{2}$ after precooling. ${ }^{2}$ Interestingly, sweat rate was similar, approximately 2.60 litres/h, between conditions. This study showed that the advantage of precooling for endurance exercise in hot humid conditions is reduced thermal strain while increasing the capacity for heat storage. It was also noted that, after precooling, during the first 20 minutes of exercise, the rate of increase in mean skin temperature was high. According to fig l, the benefit of precooling seems to be an enhanced capacity to store heat. The data clearly show that, in each of the three studies, heat storage is higher in precooled than control conditions regardless of whether the precooling method was by water immersion or cold air. This is a particularly salient point highlighted by a study that precooled the skin but not the rectal temperature while exercise was performed under warm humid conditions. ${ }^{9}$ The authors noted that the reduced $\mathrm{T}_{\mathrm{re}}$ during exercise was due primarily to the reduced skin temperature affording a greater thermal gradient. As a consequence the increased thermal gradient attenuated the rise in $\mathrm{T}_{\mathrm{re}}$ effectively reducing the likelihood of subjects reaching the critical limiting temperature.

Similarly, when the rate of heat storage was manipulated $\left(0.1^{\circ} \mathrm{C} / \mathrm{min} v 0.05^{\circ} \mathrm{C} / \mathrm{min}\right)$, it was found that subjects exercising at $60 \% \mathrm{Vo}_{2}$ PEAK reached exhaustion at similar $\mathrm{T}_{\mathrm{es}}$ and $\mathrm{T}_{\mathrm{m}}$, but with significantly different skin temperatures $\left(38.4^{\circ} \mathrm{C} v 35.6^{\circ} \mathrm{C}\right.$ for high and low rates of heat storage respectively). ${ }^{34}$ However, the difference in skin temperature between conditions was the result of contact of the water perfused jacket with the skin of the trunk and forearms. The time to exhaustion was significantly shorter for subjects in the conditions of higher than lower rate of heat storage. This study shows that high or limiting internal body temperatures are directly related to the 
rate of heat storage. Further to this point, this study shows that time to exhaustion is increased by reducing body temperature before exercise.

\section{CNS, CARDIOVASCULAR, AND METABOLIC RESPONSES TO EXERCISE AFTER PRECOOLING}

Although the cardiovascular and metabolic responses to exercise under various conditions and interventions are well documented, there are few data on similar responses after precooling. Several schools of thought exist on what limits exercise performance during exercise in the heat (for a review, see Febbraio $^{35}$ ). Clearly, the fact that exercise performance in most reported studies is improved after precooling (table 1) suggests that limiting the rate of rise in core temperature is a major determining factor. However, whether this in turn impacts on substrate availability, cardiovascular function, skeletal muscle function, or the CNS in order to limit exercise capacity still remains unclear, although a recent study ${ }^{36}$ using the critical limiting temperature model of fatigue showed that, in the presence of high internal body temperature, skeletal muscles not used during the preceding exercise bout were unable to reproduce baseline force values, implicating the CNS in the reduction of skeletal muscle force output. In general, the responses of these systems have not been studied during exercise after precooling, making it difficult to ascertain how a precooling manoeuvre may affect them.

There is an emerging consensus that fatigue during exercise in the heat may be due to a reduced CNS motor drive. This hypothesis has not been directly evaluated, but we have recently shown that there is some evidence for neuromuscular fatigue during high intensity cycling in the heat. ${ }^{31}$ In this study, subjects cycled for 60 minutes at a self selected pace, with the exercise punctuated with six one-minute sprints. It was very clear that subjects consciously exerted a maximum effort for each sprint, as evidenced by similar heart rates and increased rating of perceived exertion, but with a reduced power output and motor drive (electromyogram). In a subsequent study in which subjects self selected running speed $s^{37}$ during a 30 minute treadmill run in the heat, it was also clear that subjects altered their pacing strategy compared with a similar trial in cooler conditions to ensure that they were able to finish the run without overheating. The findings from these studies suggest that a subconscious control may have been operating to reduce the likelihood of cellular injury during such conditions. Because the terminal $\mathrm{T}_{\text {re }}$ was $39^{\circ} \mathrm{C}$, it would be logical to assume that a reduced rate of rise in $\mathrm{T}_{\mathrm{re}}$ as the result of precooling would probably attenuate the reduction in motor recruitment and thereby allow the maintenance of higher exercise intensity. However, this hypothesis has not been directly evaluated.

In contrast with the responses of the CNS, the cardiovascular system during exercise after precooling has been reasonably well studied. The assumption here is that by reducing the rate of rise in body temperature, the need for skin blood flow is reduced, thereby increasing the volume of blood available for the central circulation. This would naturally lead to an increased stroke volume and hence a reduced heart rate response for a given level of exercise intensity. Indeed, most studies show that, under steady state conditions, heart rate during exercise after precooling is attenuated. ${ }^{478}$ An analysis of the literature indicates that heart rate is lower during the initial 15 minutes of exercise after precooling, with this difference disappearing for the remaining portion of the exercise. ${ }^{28}$ In fact, heart rate at the end of exercise has been shown to be similar in control and precooling conditions irrespective of ambient temperature. Although it should be noted that more work is performed for a similar heart rate under precooled conditions, it is unclear why athletes terminate exercise at identical heart rates irrespective of the ambient temperature or thermal strain and even when self pacing. ${ }^{37}$ However, in a

\section{Take home message}

- Precooling studies confirm that increasing body heat is a limiting factor during exercise

- Precooling is probably only beneficial for endurance exercise of up to 30-40 minutes rather than intermittent or short duration exercise

- Precooling before an endurance event may be worth while if the facilities are available

- Precooling would be advantageous for endurance exercise in warm conditions

study that examined the effect of preheating and precooling on exercise time to exhaustion, it seemed clear that if the $T_{\text {es }}$ skin temperature, and skin blood flow was increased before exercise by preheating the subjects, cardiac output was reduced secondary to a diminished stroke volume. ${ }^{34}$ Interestingly, the differences in cardiovascular responses disappeared after about 10 minutes of exercise, with subjects terminating exercise at similar $\mathrm{T}_{\mathrm{es}}$, heart rate, cardiac output, and stroke volume. In addition to these data, it has also been shown that neither blood volume nor plasma volume are sufficiently attenuated to account for reduced cardiovascular strain during exercise under precooled conditions. ${ }^{38}$

Thus far the metabolic responses to exercise after precooling have not been extensively documented. Most studies indicate that oxygen consumption remains unchanged with precooling after 10 minutes of exercise, ${ }^{289}$ and that no relation exists between exercise performance and oxygen consumption after precooling. It has been proposed that precooling may enhance exercise performance by reducing the metabolic perturbation usually observed with increased body and muscle temperatures. Indeed, if the rise in core temperature is blunted during exercise, the result is an attenuation in net muscle glycogen use. ${ }^{39}$ However, a recent study showed that precooling had very limited effect on substrate provision during exercise heat stress. ${ }^{10}$ That is, despite lower $\mathrm{T}_{\mathrm{es}}$ and $\mathrm{T}_{\mathrm{m}}$ after precooling, muscle glycogen utilisation was not different at the end of exercise compared with a control trial. The authors suggested that $\mathrm{T}_{\mathrm{m}}$ may need to exceed a critical level before muscle energy metabolism is altered sufficiently to impact on exercise. It must be noted that, in this study, the muscle glycogen levels before exercise were not similar in the two trials, making these findings difficult to interpret. However, energy metabolism cannot by itself explain a reduction in exercise performance, given that substrates are never fully depleted; if they were depleted, rigor, not fatigue, would ensue.

\section{SUMMARY AND CONCLUSIONS}

The current body of evidence suggests that whole body precooling is able to increase capacity for prolonged exercise at various ambient temperatures. It is less well understood how precooling enhances high intensity exercise of short duration. It is clear, however, that precooling does allow a greater rate of heat storage, with the effect of reducing the rate of rise in core temperature a decisive advantage. In most cases, precooled subjects were able to sustain higher exercise intensity than controls, but this was not associated with any apparent metabolic or cardiovascular advantages. From the literature, it seems that precooling provides a distinct thermal advantage for exercise, particularly in the heat. Although the mechanisms that lead to enhanced exercise performance after precooling are unclear, the evidence suggests that the effect of precooling on the CNS is probably a factor. If precooling is found to be an effective strategy for enhancing exercise performance, then more studies to evaluate its practical value need to be conducted. At present, there are no descriptions of how precooling may be achieved at athletic venues. Water immersion and the use of ice vests may be more practical than 
cold air cooling. However, given the time required to achieve sufficient body cooling to produce an advantage, it seems unlikely that precooling manoeuvres will be popular at athletic events in the immediate future.

\section{REFERENCES}

1 Kay D, Marino FE. Fluid ingestion and exercise hyperthermia: implications for performance, thermoregulation, metabolism and the development of fatigue. I Sports Sci 2000;18:71-82.

2 Booth J, Marino F, Ward JJ. Improved running performance in hot humid conditions following whole body precooling. Med Sci Sports Exerc 1997;29:943-9.

3 Olschewski H, Brück K. Thermoregulatory, cardiovascular, and muscular factors related to exercise after precooling. J Appl Physiol 1988:64:803-11.

4 Schmidt V, Brück K. Effect of a precooling maeuver on body temperature and exercise performance. J Appl Physiol 1981;50:772-8.

5 Nielsen B, Hales JRS, Strange S, et al. Human circulatory and thermoregulatory adaptation with heat acclimation and exercise in a hot, dry environment. J Physiol (Lond) 1993;460:467-85.

6 Bergh U, Ekblom B. Physical performance and peak aerobic power at different body temperatures. J Appl Physiol 1979;46:885-9.

7 Hessemer V, Langusch D, Brück K, et al. Effect of slightly lowered body temperatures on endurance performance in humans. J Appl Physiol 1984:57:1731-7

8 Lee DT, Haymes EM. Exercise duration and thermoregulatory responses after whole body precooling. J Appl Physiol 1995;79:1971-6.

9 Kay D, Taaffe DR, Marino FE. Whole-body pre-cooling and heat storage during self-paced cycling performance in warm humid conditions. $J$ Sports Sci 1999:17:937-44.

10 Booth J, Wislmore BR, Macdonald AD, et al. Whole-body pre-cooling does not alter human muscle metabolism during sub-maximal exercise in the heat. Eur J Appl Physiol 2001:84:587-90.

11 Cotter JD, Sleivert GG, Roberts WS, et al. Effect of pre-cooling, with and without thigh cooling, on strain and endurance exercise performance in the heat. Comp Biochem Physiol A 2001;128:667-77.

12 Sawka MN, Young AJ, Latzka WA, et al. Human tolerance to heat strain during exercise: influence of hydration. J Appl Physiol 1992;73:772-8.

13 Bazett HC, Scott JC, Maxfield ME, et al. Effect of baths at different temperatures on oxygen exchange and on circulation. Am J Physiol 1937;1 19:93-110.

14 Gold AJ, Zornitzer A. Effect of partial body cooling on man exercising in a hot dry environment. Aerospace Medicine 1968:39:944-6.

15 Webb P, Annis JF. Cooling required to suppress sweating during work. J Appl Physiol 1968;25:489-93.

16 Falls HB, Humphrey LD. Effect of length of cold showers on skin temperatures and exercise heart rate Res Q 1970:41:353-60.

17 Falls HB, Humphrey LD. Cold water application effects on responses to heat stress during exercise. Res Q 1971;42:21-9.

18 Veghte JH, Webb P. Body cooling and response to heat. J Appl Physiol $1961 ; 16: 235-8$
19 Lloyd E. Hypothermia and cold stress. Sydney: Croom Helm, 1986.

20 Kruk B, Pekkarinen H, Manninen K, et al. Comparison in men of physiological responses to exercise of increasing intensity at low and moderate ambient tempeartures. Eur J Appl Physiol 1990;62:353-7.

21 Romet TT. Mechanism of afterdrop after cold water immersion. J Appl Physiol 1988;65:1535-8.

22 Webb P. Afterdrop of body temperature during rewarming: an alternative explanation. J Appl Physiol 1986;60:385-90.

23 Marino F, Booth J. Whole body cooling by immersion in water at moderate temperatures. J Sci Med Sport 1998;1:72-81.

24 Molnar GW. Survival of hypothermia by men immersed in the ocean. JAMA 1946;131:1046-50

25 Smith RM, Hanna JM. Skinfolds and resting heat loss in cold air and water: temperature equivalence. J Appl Physiol 1975;39:93-102.

26 Drust B, Cable NT, Reilly T. Investigation of the effects of the pre-cooling on the physiological responses to soccer-specific intermittent exercise. Eur J Appl Physiol 2000;81:11-17.

27 Sleivert GG, Cotter JD, Roberts WS, et al. The influence of whole-body vs. torso pre-cooling on physiological strain and performance of high-intensity exercise in the heat. Comp Biochem Physiol A 2001;128:657-66.

28 Blomstrand E, Bergh U, Essen-Gustavsson B, et al. Influence of low muscle temperature on muscle metabolism during intense dynamic exercise. Acta Physiol Scand 1984;1 20:229-36.

29 Marsh D, Sleivert G. Effect of precooling on high intensity cycling performance. Br J Sports Med 1999;33:393-7.

30 Ball D, Burrows C, Sargeant AJ. Human power output during repeated sprint cycle exercise: the influence of thermal stress. Eur J Appl Physiol 1999;79:360-6.

31 Kay D, Marino FE, Cannon J, et al. Evidence for neuromuscular fatigue during high-intensity cycling in warm, humid conditions. Eur J Appl Physiol 2001;84:115-21.

32 Bolster DR, Trappe SWKR, Scheffield-More MA, et al. Effects of precooling on thermoregulation during subsequent exercise. Med Sci Sports Exerc 1999:31:251-7.

33 Nielsen B. Olympics in Atlanta: a fight against physics. Med Sci Sports Exerc 1996;28:665-8.

34 González-Alonso J, Teller C, Andersen SL, et al. Influence of body temperature on the development of fatigue during prolonged exercise in the heat. J Appl Physiol 1999:86:1032-9.

35 Febbraio MA. Does muscle function and metabolism affect exercise performance in the heat? Exerc Sports Sci Rev 2000;28:171-6.

36 Nybo L, Nielsen B. Hyperthermia and central fatigue during prolonged exercise in humans. J Appl Physiol 2001;91:1055-60.

37 Marino FE, Mbambo Z, Kortekaas E, et al. Advantages of smaller body mass during distance running in warm, humid environments. Pflüg Arch 2000;441:359-67.

38 Marino FE, Booth J. Cardiovascular responses to self-paced running in warm humid conditions following whole-body precooling. South African Journal of Sports Medicine 2001:8:3-8.

39 Febbraio M, Snow RJ, Stathis CG, et al. Blunting the rise in body temperature reduces muscle glycogenolysis during exercise in humans. Exp Physiol 1996:81:685-93.

\section{Editorial office address}

Please note that the editorial office of British Journal of Sports Medicine has moved. Please send all future communications to:

Dr Paul McCrory,

British Journal of Sports Medicine,

Centre for Sports Medicine Research \& Education,

School of Physiotherapy,

Level 1, 200 Berkeley Street,

Parkville, Victoria 3052,

Australia;

Tel: +6138344 4118; Fax: +6138344 3771;

Email: bjsm@BMgroup.com 